\title{
Thermomechanical Assessment of Plastic Deformation in Model Amorphous Polyamide/Clay Nanocomposites
}

\author{
Kunal Tulsyan,, ${ }^{1}$ Saurabh Toshniwal, ${ }^{1}$ Gowri Dorairaju,, ${ }^{1}$ Daniel F. Schmidt, ${ }^{1}$ \\ and Emmanuelle Reynaud ${ }^{2}$ \\ ${ }^{1}$ Department of Plastics Engineering, University of Massachusetts Lowell, One University Avenue, Lowell, MA 01854, USA \\ ${ }^{2}$ Department of Mechanical Engineering, University of Massachusetts Lowell, One University Avenue, Lowell, MA 01854, USA
}

Correspondence should be addressed to Emmanuelle Reynaud, emmanuelle_reynaud@uml.edu

Received 11 January 2010; Accepted 22 March 2010

Academic Editor: Frank T. Fisher

Copyright ( $) 2010$ Kunal Tulsyan et al. This is an open access article distributed under the Creative Commons Attribution License, which permits unrestricted use, distribution, and reproduction in any medium, provided the original work is properly cited.

In an effort to isolate the role of nanofiller independent of changes in polymer microstructure, we report the processing and characterization of model amorphous polyamide/clay nanocomposites. Analyses confirm fully amorphous character, no change in $T_{\mathrm{g}}$ or thermal stability, and a partially exfoliated structure. The tensile modulus, yield stress, and failure stress increase with the clay content, both in dried and conditioned samples. In contrast, failure strain decreases with increasing clay content in conditioned samples but is independent of clay content in dried samples. Concurrently, the conversion of mechanical work to heat during plastic deformation was studied using infrared thermography, with the heat of deformation estimated based on these results and compared to the work of deformation. These results allow us to quantify changes in deformation mechanism and to conclude that the presence of clay enhances the conversion of mechanical energy to heat in these materials.

\section{Introduction}

Polymer nanocomposites have generated significant interest among both academic and industrial researchers thanks to the various properties enhancements that may be realized in such systems versus the neat resins alone. Achieving such enhancements means realizing thermodynamic compatibility between the nanoparticle and the polymer matrix. Likewise, most polymers with the needed polarity to achieve such compatibility with commonly used nanoparticles based on silica, silicates, and other polar metal oxide derivatives are semicrystalline in nature. While various literature models attempt to account for the mechanical properties enhancements observed in polymer nanocomposites, in general they neglect nanoparticle-induced variations in polymer microstructure. That said, a large body of the publications dealing with polyamide/clay nanocomposites demonstrates that the clays induce a change in the crystalline form. Likewise, conflicting literature reports indicate increased, decreased, or unchanged overall crystallinity in these systems [1, 2]. Furthermore, it is likely that such changes affect the mechanical properties of these materials [1, 3].
Building on this observation, the goal of the present study is to isolate the effect of the nanofiller alone on the mechanical properties of a model nanocomposite while ensuring high levels of nanoscale dispersion. In particular, we report the production by conventional melt-processing techniques (twin-screw extrusion and injection molding) and the characterization of a polymer nanocomposite based on a fully amorphous yet polar matrix. By eliminating the presence of crystallinity while retaining high polarity, the effect of reinforcement by dispersed clay layers may be studied independent of changes in polymer microstructure.

\section{Experimental}

2.1. Materials and Processing. Grilamid TR-90 (EMS Grivory), a fully amorphous copolyamide, was selected as the basis for this work; its structure is illustrated in Figure 1. This polymer has processing characteristics similar to those of polyamide 6 (PA 6) and polarity similar to that of polyamide 12 (PA 12), allowing for comparisons with literature reports involving semi-crystalline polyamides. 




FIgure 1: Chemical structure of Grilamid TR-90 [4].

Cloisite 30B (Southern Clay Products), a bis(2-hydroxyethyl)methyl tallow ammonium-modified montmorillonite clay, was chosen as the nanofiller for this effort, given its proven compatibility with a range of polyamides [5-15].

Amorphous copolyamide pellets and clay powder were dry blended to produce mixtures with inorganic contents of $0.125,0.25,0.5$, and $1 \%$ by volume. This concentration range was chosen so that all nanocomposites compared here fall below the percolation threshold for platelets with aspect ratios of $100(\sim 1.2 \mathrm{vol} . \%)$ [16], ensuring that the dispersion states realized are comparable and independent of clay content. The nanocomposite naming convention used here is TR90-Cl30B-X, where $\mathrm{X}$ is the volume percent of clay platelets (considering inorganic content only), the relevant concentration as far as all mechanical models are concerned.

All samples (including clay-free polymer) were fed via a volumetric feeder into an intermeshing $27 \mathrm{~mm}$ corotating twin-screw extruder (Leistritz ZSE 27HP-40D) with an L/D ratio of $40: 1$. Based on the screw programming recommended by Nanocor to produce semicrystalline polyamide nanocomposites [17], a high-shear twin-screw extrusion profile with three sections of kneading blocks was used. As minimizing moisture content is critical in this process, a vent zone was present midway down the extruder barrel. A vacuum-assisted vent zone at the end of the barrel was used for the same purpose. A room-temperature water bath was used for cooling the strand exiting the die, which was then pelletized using a pelletizer (Reduction Engineering model 604).

Following extrusion, each formulation was first dried under vacuum at $80^{\circ} \mathrm{C}$ for twelve hours before molding. Injection molding of ASTM D638 Type I tensile test specimens was then performed using a Milacron FANUC 55 ton Roboshot (Model S200i 55B) unit.

\subsection{Characterization}

2.2.1. X-Ray Diffraction (XRD). Wide-angle X-ray scattering (WAXS) measurements were carried out using a Bruker Instruments D8 DISCOVER/GADDS system $(40 \mathrm{kV}, 40 \mathrm{~mA}$, $\mathrm{Cu} \mathrm{K} \alpha$ radiation, $\lambda=0.15418 \mathrm{~nm}$ ). Specimens cut from the center of tensile bars were used for this purpose, and FIT2D v12.077 was used to generate 2-theta versus intensity plots from the 2D WAXS patterns.

Small-angle X-ray scattering (SAXS) data was recorded using a Statton camera/image plate X-ray diffraction system based on a Rigaku ultraX generator $(50 \mathrm{kV}, 200 \mathrm{~mA}, \mathrm{Cu} \mathrm{K} \alpha$ radiation, $\lambda=0.15418 \mathrm{~nm}$ ).
2.2.2. Transmission Electron Microscopy (TEM). Transmission electron microscopy was performed using a Philips EM 400T transmission electron microscope $(100 \mathrm{kV})$. The sample was first microtomed into thin sections $(t \sim 100 \mathrm{~nm})$ using a Leica EM UC6 ultramicrotome equipped with a diamond knife and operated at room temperature.

2.2.3. Thermogravimetric Analysis (TGA). TGA was performed using a TA instruments Q50 TGA. Specimens were heated to $850^{\circ} \mathrm{C}$ at a rate of $20^{\circ} \mathrm{C} / \mathrm{min}$ in a platinum pan in flowing ultra zero air $(60 \mathrm{~mL} / \mathrm{min})$. In addition, in order to evaluate the rate of degradation, the first derivative of the standard TGA curves was taken with respect to temperature; these curves are referred to as dTGA curves.

2.2.4. Differential Scanning Calorimetry (DSC). DSC was conducted using a TA instruments Q200 DSC in an ultra high-purity helium environment using heating and cooling rates of $10^{\circ} \mathrm{C} / \mathrm{min}$ in the temperature range of $-50^{\circ} \mathrm{C}$ to $320^{\circ} \mathrm{C}$.

2.2.5. Tensile Testing. Tensile testing was performed using an Instron 6025 universal testing machine as per ASTM D638, using the Type I tensile bars previously described. At least ten specimens of each formulation were tested at a strain rate of $50 \mathrm{~mm} / \mathrm{min}$ and with a gauge length of $100 \mathrm{~mm}$. The test specimens were conditioned before testing for 48 hours at $50 \%$ relative humidity and $23^{\circ} \mathrm{C}$ as per ASTM D618. A second set of samples were dried at $80^{\circ} \mathrm{C}$ in a vacuum oven for twelve hours and otherwise tested as per ASTM D638 to identify the effect of moisture on the mechanical properties. Materials availability also allowed a smaller number of specimens to have their maximum surface temperature recorded using a FLIR Systems Thermovision A20M infrared camera during tensile testing.

\section{Results and Discussion}

3.1. Nanocomposite Composition. Prior to all other analyses, the actual concentration of clay in the nanocomposites was determined via TGA. These calculations accounted for both residue from nonclay sources (based on TGA data for unfilled polymer with the same process history) and high-temperature dehydroxylation of the clay layers (as determined via TGA of the clay alone). The results of these analyses are shown in Table 1, with variations reported being the standard deviations based on three independent analyses of each formulation. Note that "clay" in this context refers to the alkylammonium-modified clay, while "inorganic" 
TABLE 1: Nanocomposite compositions (actual values measured via three independent TGA measurements).

\begin{tabular}{lcccc}
\hline & \multicolumn{2}{c}{ Desired composition } & \multicolumn{2}{c}{ Actual composition } \\
Nanocomposite & Inorganic (vol. \%) & Clay (wt \%) & Inorganic (vol. \%) & Clay (wt\%) \\
\hline TR90-Cl30B-0.125 & 0.125 & 0.51 & $0.11 \pm 0.02$ & $0.42 \pm 0.07$ \\
TR90-Cl30B-0.25 & 0.25 & 1.01 & $0.23 \pm 0.01$ & $0.89 \pm 0.04$ \\
TR90-Cl30B-0.5 & 0.5 & 2.02 & $0.50 \pm 0.02$ & $1.93 \pm 0.08$ \\
TR90-Cl30B-1 & 1 & 4 & $0.91 \pm 0.02$ & $3.47 \pm 0.07$ \\
\hline
\end{tabular}

refers only to the silicate layers themselves, excluding the alkylammonium modifier.

3.2. Nanocomposite Structure. Clay dispersion levels were assessed via SAXS and WAXS on a central cross-section of injection-molded tensile bars of each composition, with additional confirmation via TEM. The reported $d$-spacing of Cloisite $30 \mathrm{~B}$ is $18.5 \AA$ [18]. Figure 2 shows an overlay plot of X-ray intensity versus $2 \theta$ obtained from WAXS for all nanocomposites studied. A small peak can be observed at $6^{\circ}$, corresponding to a $d$-spacing of $14.7 \AA$ or $29.4 \AA$, corresponding to either the first- or the second-order diffraction peak. A value of $14.7 \AA$ is unlikely, as it would imply that the platelets have collapsed on one another, inconsistent with our TEM observations. We therefore interpret this as a second-order diffraction peak, indicative of the presence of intercalated clay layers, with the first-order diffraction peak obscured by the intensity of the incident beam. The peaks observed at $\sim 9^{\circ}$ and $\sim 18^{\circ}$ correspond to the amorphous halo (i.e., scattering from the amorphous domains of the polymer) [19], and are effectively independent of clay content in terms of both position and intensity, supporting the lack of microstructural changes in the polymer phase.

2D SAXS and WAXS patterns for the center section of a TR90-Cl30B-1 tensile specimen are shown in Figure 3. These false color images reveal the orientation of the clay layers in the flow direction and parallel to the long axis of the tensile bar cross-section. The dark line observed in the lower-left quadrant of the SAXS pattern comes from the beam-stop, while the unbroken rings observed on the WAXS pattern correspond to the unoriented amorphous halo of the polymer.

The state of dispersion was further studied by TEM (representative image shown in Figure 4), which indicated the presence of both individual clay layers and thin stacks and confirmed some level of parallel orientation. When coupled with the WAXS and SAXS data, we conclude that these systems are partially exfoliated and oriented in the direction of the flow of the polymer melt in the tensile bar.

3.3. Thermal Behavior. A heat-cool-heat DSC analysis was used to confirm the fully amorphous nature of the copolyamide matrix and to assess whether any changes in thermal properties had occurred as a result of the presence of the clay. The values for the glass transition temperature from the first and second heating cycles $\left(T_{\mathrm{gI}}\right.$ and $T_{\mathrm{gII}}$, resp.) are reported in Table 2. In all cases, a transition very close

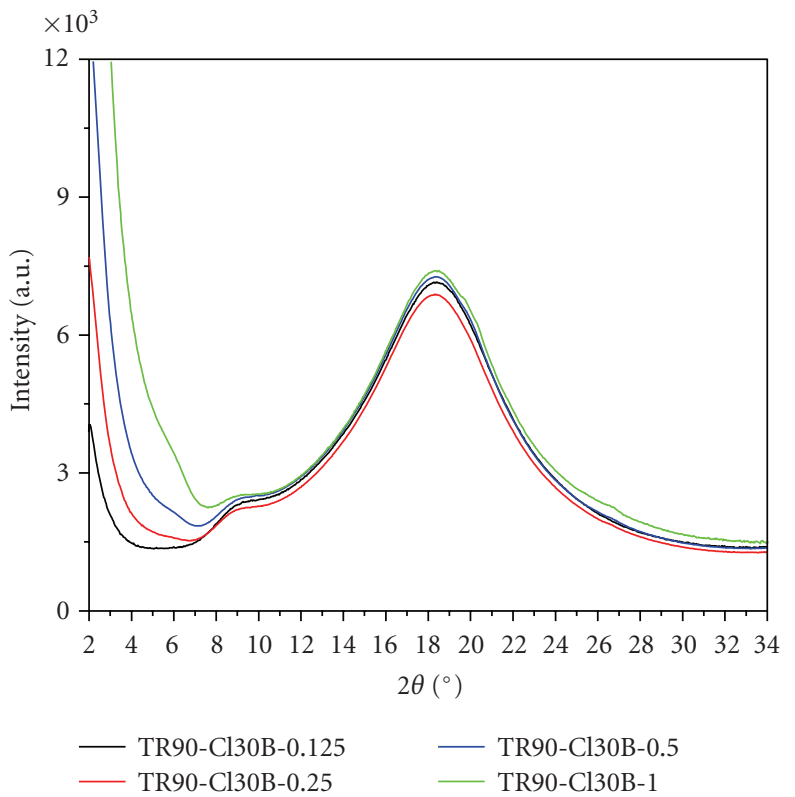

FIGURE 2: 1D WAXS data for the TR90-Cl30B nanocomposite system.

TABLE 2: $T_{\mathrm{g}}$ values for the TR90-Cl30B nanocomposite system (each value derived from a single DSC heating cycle).

\begin{tabular}{lcc}
\hline Material & $T_{\mathrm{gl}}\left({ }^{\circ} \mathrm{C}\right)$ & $\left.T_{\mathrm{gII}}{ }^{\circ} \mathrm{C}\right)$ \\
\hline TR90 & 141 & 153 \\
TR90-Cl30B-0.125 & 137 & 152 \\
TR90-Cl30B-0.25 & 145 & 151 \\
TR90-Cl30B-0.5 & 138 & 149 \\
TR90-Cl30B-1 & 146 & 149 \\
\hline
\end{tabular}

to the documented $T_{\mathrm{g}}$ of $157^{\circ} \mathrm{C}$ is observed [20], with this difference easily explained by differences in analytical parameters. There is no indication of melting during heating or crystallization during cooling in the pure polymer or any of the nanocomposites, confirming their amorphous nature. Finally, there is no particular trend in the evolution of the $T_{\mathrm{g}}$ or the size or shape of the transition versus clay content.

In addition to its utility in confirming the actual clay content, TGA was also used to assess the thermal stability of the nanocomposites studied here. In general it was observed that the peak in the dTGA curve increased in intensity and decreased in width with increasing clay content, consistent 


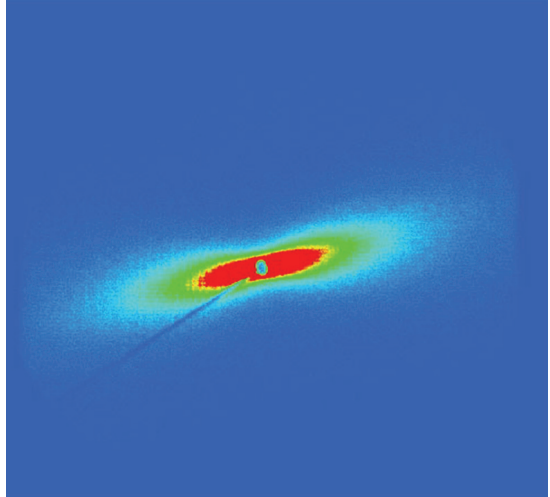

(a)

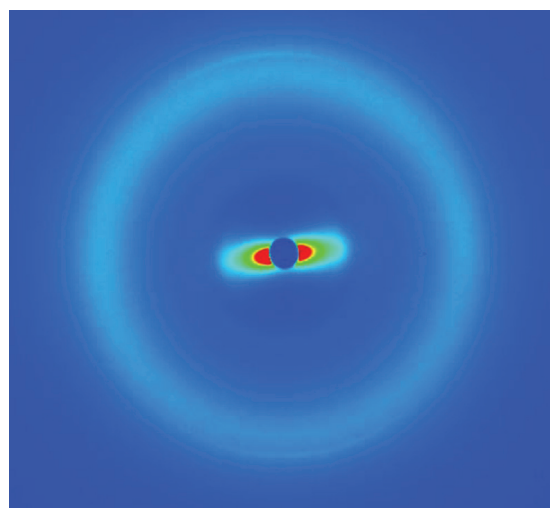

(b)

FIgURe 3: 2D SAXS (a) and 2D WAXS (b) data for TR90-Cl30B-1.

TABLE 3: $T_{\text {onset }}$ and $T_{\max }$ values for TR90-Cl30B nanocomposite system and its components (each value derived from the average of three independent TGA measurements).

\begin{tabular}{lcc}
\hline Material & $T_{\text {onset }}\left({ }^{\circ} \mathrm{C}\right)$ & $T_{\max }\left({ }^{\circ} \mathrm{C}\right)$ \\
\hline Cloisite 30B & 255 & 260 \\
TR90 & $411 \pm 2$ & $454 \pm 4$ \\
TR90-Cl30B-0.125 & $412 \pm 1$ & $465 \pm 3$ \\
TR90-Cl30B-0.25 & $413 \pm 1$ & $460 \pm 2$ \\
TR90-Cl30B-0.5 & $414 \pm 2$ & $465 \pm 4$ \\
TR90-Cl30B-1 & $416 \pm 3$ & $460 \pm 6$ \\
\hline
\end{tabular}

with a clay-induced increase in the maximum degradation rate over a narrower range of temperatures. Table 3 presents a more complete picture of the dTGA results with respect to the temperature at $5 \%$ weight loss $\left(T_{\text {onset }}\right)$ and the temperature at which the maximum degradation rate is observed $\left(T_{\max }\right)$. As this data clearly shows, the clay has little or no effect on the thermal stability of the polymer matrix as measured via TGA.

3.4. Mechanical Properties. As noted previously, mechanical properties were measured for both conditioned $\left(23^{\circ} \mathrm{C}, 50 \%\right.$

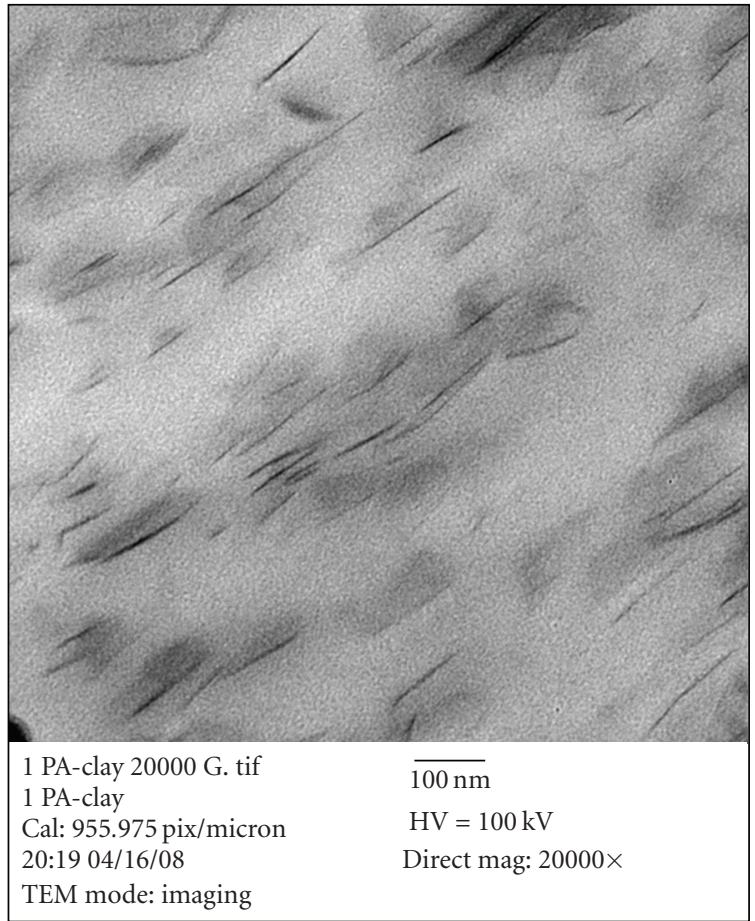

FIgURE 4: Representative TEM image for TR90-Cl30B-1.

relative humidity, 48 hours) and dried $\left(80^{\circ} \mathrm{C}\right.$ under vacuum for 12 hours) materials to assess the effects of moisture on the underlying properties. The results of these efforts are summarized in Tables 4 and 5, with the number of samples tested indicated parenthetically adjacent to the material designation.

We begin the discussion of these properties with a consideration of the evolution of the tensile modulus, as illustrated in Figure 5.

While more variation is observed in the data from the dried samples, the TR90-Cl30B nanocomposite system generally shows an increase in tensile modulus with increasing clay content. These results are consistent with literature results obtained in analogous semi-crystalline polyamide/clay nanocomposites [21], where an increase of $30-40 \%$ in tensile modulus is observed at clay concentrations similar to the highest investigated here.

We now turn our attention to the yield stress trends, as illustrated in Figure 6. The yield stress was observed to follow a very similar (though less pronounced) trend, with an increase of $\sim 12 \%$ at the highest clay concentration investigated here. Drying increases the yield stress by $5-10 \%$ but the relative trend remains the same. As above, a literature report by Fornes et al. [22] indicates a $\sim 10-15 \%$ increase in yield stress in an analogous polyamide 6/clay system. In terms of yield strain (data presented in Tables 4 and 5), the presence of the clay results in an earlier transition from elastic to plastic deformation, with both the conditioned and dried TR90-Cl30B nanocomposites showing a gradual decrease in yield strain values with increasing clay content. Drying slightly increases yield strain, perhaps due to the lack of moisture-induced plasticization. 
TABLE 4: Mechanical properties data for conditioned samples $\left(23^{\circ} \mathrm{C}, 50 \% \mathrm{RH}, 48\right.$ hours $)$.

\begin{tabular}{lccccc}
\hline Material & Tensile modulus $(\mathrm{GPa})$ & Yield strain $(\%)$ & Yield stress $(\mathrm{MPa})$ & Failure strain $(\%)$ & Failure stress $(\mathrm{MPa})$ \\
\hline TR90 $(n=10)$ & $1.14 \pm 0.02$ & $10.5 \pm 0.3$ & $58.7 \pm 0.7$ & $99 \pm 24$ & $43.8 \pm 2.2$ \\
TR90-Cl30B-0.125 $(n=10)$ & $1.18 \pm 0.02$ & $10.3 \pm 0.2$ & $58.8 \pm 0.7$ & $70 \pm 15$ & $41.6 \pm 2.1$ \\
TR90-Cl30B-0.25 $(n=9)$ & $1.22 \pm 0.02$ & $10.1 \pm 0.2$ & $60.0 \pm 1.0$ & $85 \pm 25$ & $43.8 \pm 2.2$ \\
TR90-Cl30B-0.5 $(n=10)$ & $1.29 \pm 0.03$ & $9.7 \pm 0.2$ & $62.3 \pm 0.9$ & $45 \pm 17$ & $45.3 \pm 2.1$ \\
TR90-Cl30B-1 $(n=10)$ & $1.44 \pm 0.05$ & $9.0 \pm 0.3$ & $64.7 \pm 0.6$ & $38 \pm 10$ & $47.8 \pm 2.3$ \\
\hline
\end{tabular}

TABLE 5: Mechanical properties data for dried samples ( $80^{\circ} \mathrm{C}$ under vacuum, 12 hours).

\begin{tabular}{lccccc}
\hline Material & Tensile modulus $(\mathrm{GPa})$ & Yield strain $(\%)$ & Yield stress $(\mathrm{MPa})$ & Failure strain $(\%)$ & Failure stress $(\mathrm{MPa})$ \\
\hline TR90 $(n=10)$ & $0.98 \pm 0.13$ & $11.1 \pm 0.5$ & $62.7 \pm 0.7$ & $60 \pm 31$ & $44.1 \pm 0.4$ \\
TR90-Cl30B-0.125 $(n=10)$ & $1.08 \pm 0.06$ & $10.8 \pm 0.5$ & $64.9 \pm 0.9$ & $37 \pm 15$ & $42.9 \pm 1.7$ \\
TR90-Cl30B-0.5 $(n=10)$ & $1.13 \pm 0.04$ & $10.3 \pm 0.3$ & $65.6 \pm 1.3$ & $61 \pm 46$ & $47.1 \pm 3.3$ \\
\hline
\end{tabular}

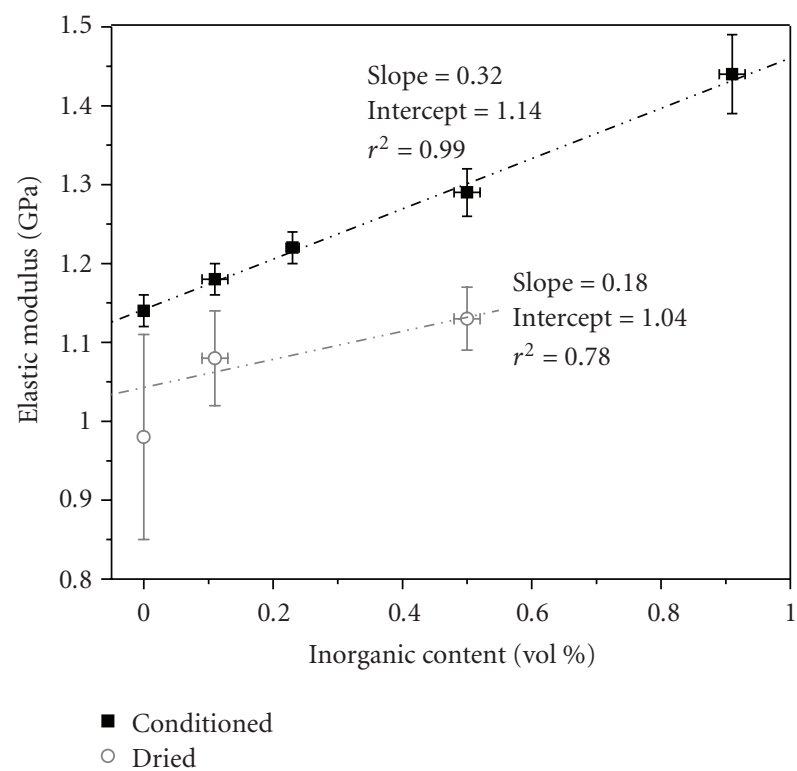

FIGURE 5: Evolution of the tensile modulus with the filler content for both conditioned and dried samples (lines are error-weighted linear fits of the experimental data).

Finally, observations may be made regarding the failure stress as well. The TR90-Cl30B nanocomposite system shows some variability in stress at failure in both the dried and the conditioned systems but with an overall increasing trend versus clay content and with no significant moisture effects, as shown in Figure 7.

Strain at failure data is shown graphically in Figure 8. While the variations in strain at failure are significant, there appears to be a decreasing trend in strain at failure versus clay content in the conditioned state. This is consistent with the observation of embrittlement in a range of analogous polyamide nanocomposites tested following identical conditioning procedures [23]. In contrast, no significant trend is observed in the dry state. When dried, polyamides are known to show reductions in failure strain, as we observe in the pure polyamide system. That said, a shift from a

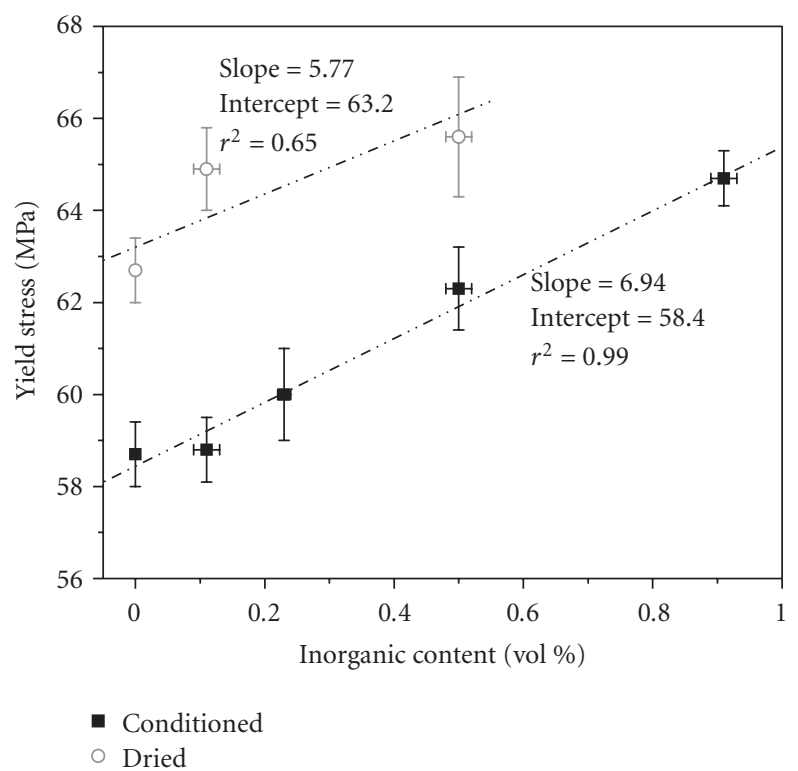

Figure 6: Evolution of the yield point with filler content for both conditioned and dried samples (lines are error weighted linear fits of the experimental data).

decreasing trend in the presence of moisture to no trend in its absence is difficult to completely explain by lack of water-induced plasticization alone, and would seem to imply a change in polymer/clay interactions. While further study is required to positively identify the nature of these changes, one clue from the literature that may support this conclusion is the report of Xie et al. [24], which shows ATR-FTIR evidence of obvious changes in hydrogenbonding patterns in analogous polyamide- 6 nanocomposites following 6 hours at $80^{\circ} \mathrm{C}$ under vacuum. While some of this may be ascribed to changes in polymer microstructure, a reduction in water content during this process cannot be ruled out as a contributing factor.

Having covered conventional mechanical properties testing, we will now address the use of an IR camera to observe changes in the specimen temperature during the 


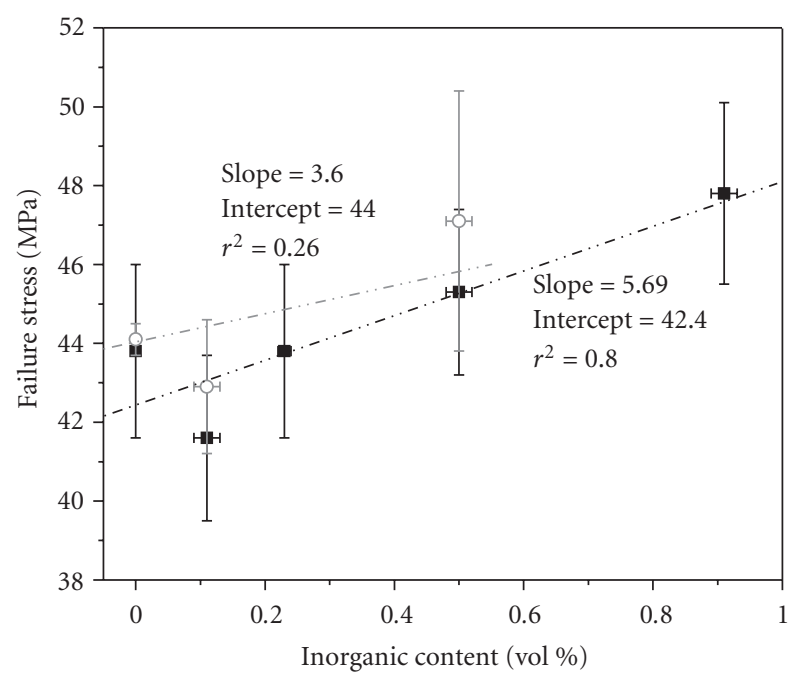

- Conditioned

○ Dried

FIGURE 7: Evolution of the tensile strength with the filler content for both conditioned and dried samples (lines are error-weighted linear fits of the experimental data).

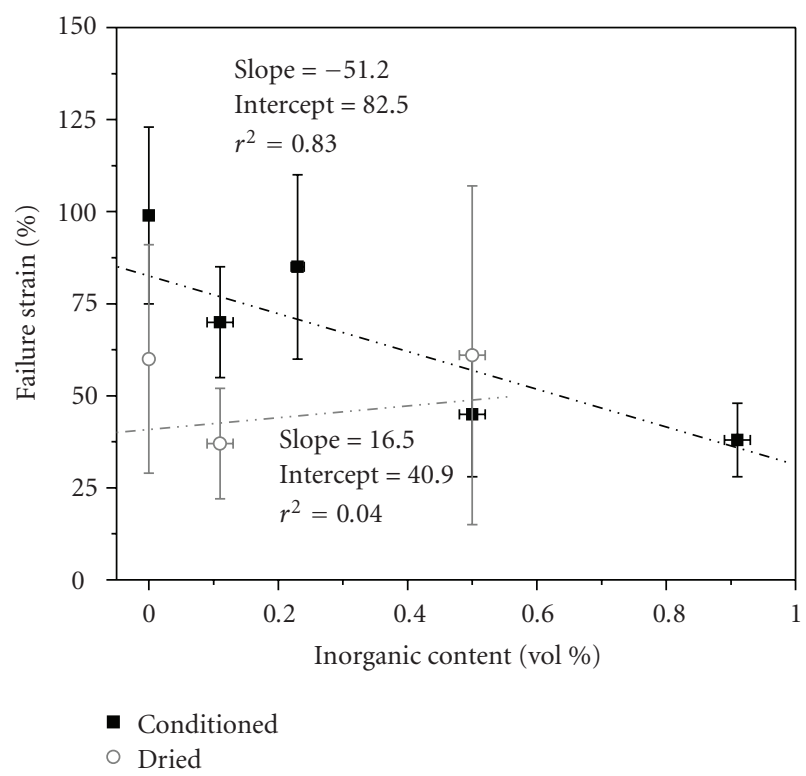

FIGURE 8: Strain at failure versus filler content for both conditioned and dried samples (lines are error-weighted linear fits of the experimental data).

tensile testing of selected specimens. No significant increase in the temperature was observed until the yield point, at which point the temperature increased, then stabilized on further elongation to produce what we term the yield plateau in the stress-temperature data. Most samples also displayed a sudden rise in temperature at the point of failure. Representative IR images in the prenecking, necking, and postfracture regimes are shown in Figure 9. The data obtained for maximum temperature versus time was then



FIGURE 9: Representative IR pictures of a sample at different stages during tensile deformation.



FIGURE 10: A representative stress-strain-temperature curve for a TR90-Cl30B-0.5 sample.

correlated with the tensile data to generate a stress-straintemperature curve of the type shown in Figure 10.

The data collected by the IR camera was then used to evaluate the amount of thermal energy liberated by the sample during plastic deformation. In particular, following baseline subtraction based on the initial temperature reading prior to yield, the area under the temperature curve was calculated for each specimen, correcting for the clay content (as only the polymer plastically deforms). This corrected area was then multiplied by the heat capacity $\left(C_{p}=2000 \mathrm{~J} / \mathrm{kg} \cdot \mathrm{K}\right.$ [25]) and density ( $\left.\rho=1010 \mathrm{~kg} / \mathrm{m}^{3}[26]\right)$ of the polymer to estimate the heat of deformation in units of energy per unit volume of polymer.

Figure 11 illustrates the linear relationship observed between thermal energy output (the aforementioned estimated heat of deformation) and the mechanical energy input (area under the post-yield portion of the stress-strain curve) during the plastic deformation. Here we observe that, regardless of sample conditioning or any tendency to fail earlier versus later in the tensile test, the thermal energy liberated is directly proportional to the mechanical energy input. An additional practical benefit of this approach is 


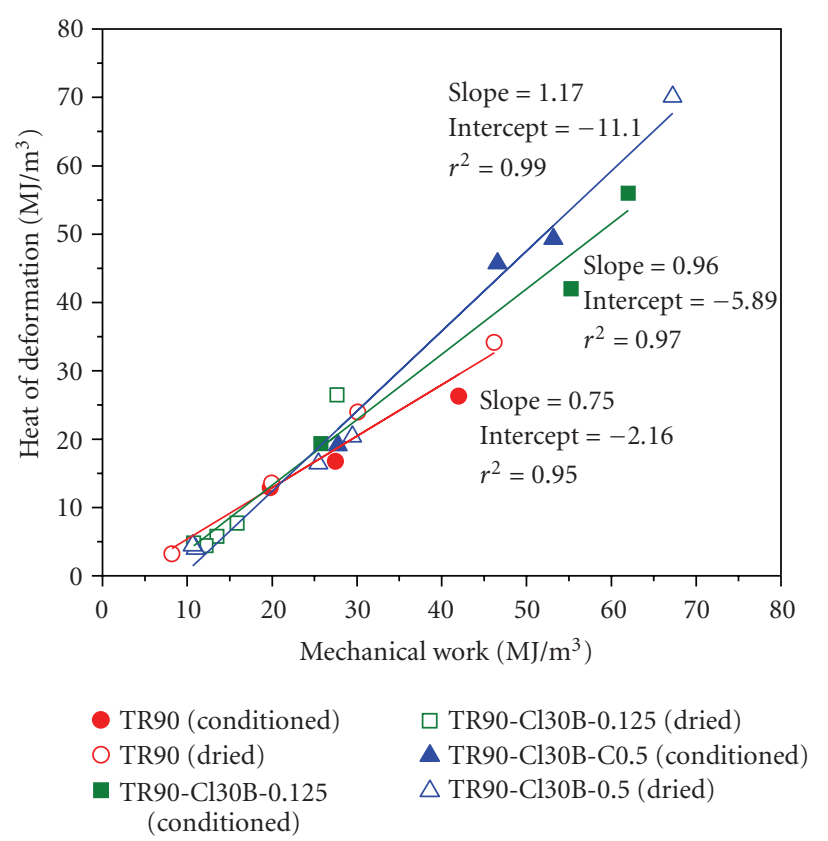

Figure 11: Thermal energy versus mechanical energy input of the TR90 composites, both conditioned (solid symbols) and dried (open symbols).

that it is able to produce such clear trends using engineering stress and strain, which tend to underestimate the work of deformation. Furthermore, the slopes of these lines show evenly spaced, statistically significant increases with increasing clay content, indicating that the presence of the clay nanoparticles enhances the ability of the polymer to convert work to heat. As reported by McNally et al. [27] for a polyamide-12 nanocomposite system, the clay particles are thought to enable other heat mechanisms to contribute to the generation of additional heat above and beyond the adiabatic heating observed in the virgin polymer. In particular, loading-induced friction at the polymer/clay interface as well as debonding and cavitation in and around clay particles could all contribute to increases in temperature.

We believe that this combined thermal/mechanical testing method is a very convenient means of assessing the influence of the nanofiller on the macroscopic behavior of a polymer. In particular, this approach enables us to shed new light on the ability of polymer nanocomposites to convert work to heat during plastic deformation. The insensitivity of these results to moisture content and early versus late failure represents a significant benefit, as compared to the high degree of variability typically observed in conventional mechanical testing of moisture-sensitive polymers due to changes in moisture content, the presence of flaws, and so forth. Likewise, thanks to the amorphous character of the matrix, its compatibility with the clay, and the use of concentrations below the percolation threshold, we may conclude that the effects observed arise as a direct result of variations in concentration of the dispersed clay layers, independent of dispersion state and polymer microstructure (both comparable for all samples).
The generation of heat during the necking of semicrystalline polymers was noted at least as far back as 1960 [28], while Haward et al. [29-31] and Roseen [32] first applied infrared thermography to the deformation of semicrystalline polymers in the mid 1970s. With that said, the use of this technique to study the plastic deformation of amorphous polymers has received much less attention, and we believe this to be the first attempt to quantify the thermomechanical behavior of filled polymers and of nanocomposites in particular. These results will be confirmed and extended via ongoing studies of comparable amorphous and semi-crystalline nanocomposite systems to evaluate the role of polymer microstructure as well as clay content.

\section{Conclusions}

Nanocomposites based on a completely amorphous nylon (Grilamid TR90) in combination with organically modified montmorillonite clay (Cloisite 30B) were successfully prepared. These nanocomposites were characterized as partially exfoliated based on SAXS, WAXS, and TEM data and consistent with literature reports for polyamide nanocomposites in general. Thermal analysis (TGA, DSC) confirmed the composition and amorphous character of the materials studied and showed no major changes in either the glass transition temperature or the thermal stability as a function of clay content.

Conventional tensile testing indicated that the tensile modulus was significantly improved with increasing clay content in conditioned samples, and to a lesser extent in dried samples, a trend reflected in other measures of reinforcement as well. Elongation at break for the conditioned TR90-Cl30B materials was highly scattered but observed to decrease with increased clay content, whereas no apparent effect of clay content was observed in the dried samples.

In addition, a new approach to the mechanical testing of nanocomposites was applied for the first time, involving simultaneous IR imaging and tensile testing, and a means of extracting an estimate of the heat of (plastic) deformation was reported. A linear relationship was observed between mechanical energy input and thermal energy output during plastic deformation for each composition studied, regardless of moisture content or failure point. A trend was seen with respect to clay content, however, with the addition of clay enhancing the conversion of mechanical energy to heat.

This work represents an initial step in a series of comparisons on the influence of the presence or absence of crystallinity on the thermomechanical behavior of polymer nanocomposites. It is hoped that this work will lead to an improved understanding of post-yield properties in this important class of materials, and confirm the utility of our approach as a means of quantifying changes in deformation behavior.

\section{Acknowledgments}

This work was supported by the National Science Foundation as a Nanoscale Science and Engineering Centers Program 
(Award no. NSF-0425826). The authors would like to thank Professor Stephen Orroth and the UML Department of Plastics Engineering for access to the Processing equipment and general support; the UML Advanced Composite Materials and Textile Research Laboratory for use of the infrared camera; Dr. Earl Ada and Mr. Chris Santeufemio from the UML Materials Characterization Lab for the SEM-EDS, TEM sectioning, and imaging; Mr. Erik Dunkerley and the UML Center for High-Rate Nanomanufacturing for assistance with thermal analysis (TGA, DSC); Dr. Hilmar Koerner, Dr. Rich Vaia et al. of the United States Air Force Research Labs for the X-ray diffraction data; and Mr. Louis Freitas of EMSGrivory America for the donation of the Grilamid TR 90.

\section{References}

[1] E. Picard, A. Vermogen, J.-F. Gérard, and E. Espuche, "Barrier properties of nylon 6-montmorillonite nanocomposite membranes prepared by melt blending: influence of the clay content and dispersion state: consequences on modelling," Journal of Membrane Science, vol. 292, no. 1-2, pp. 133-144, 2007.

[2] A. N. Wilkinson, Z. Man, J. L. Stanford, et al., "Structure and dynamic mechanical properties of melt intercalated polyamide 6-montmorillonite nanocomposites," Macromolecular Materials and Engineering, vol. 291, no. 8, pp. 917-928, 2006.

[3] Y. Zhang, J. H. Yang, T. S. Ellis, and J. Shi, "Crystal structures and their effects on the properties of polyamide 12/clay and polyamide 6-polyamide 66/clay nanocomposites," Journal of Applied Polymer Science, vol. 100, no. 6, pp. 4782-4794, 2006.

[4] H. J. Kim and H. G. Jeon, US patent US2006166762, 2006.

[5] M. Mehrabzadeh and M. R. Kamal, "Melt processing of PA66/clay, HDPE/clay and HDPE/PA-66/clay nanocomposites," Polymer Engineering and Science, vol. 44, no. 6, pp. 1152-1161, 2004.

[6] D. Homminga, B. Goderis, S. Hoffman, H. Reynaers, and G. Groeninckx, "Influence of shear flow on the preparation of polymer layered silicate nanocomposites," Polymer, vol. 46, no. 23, pp. 9941-9954, 2005.

[7] F.-C. Chiu, S.-M. Lai, Y.-L. Chen, and T.-H. Lee, "Investigation on the polyamide 6/organoclay nanocomposites with or without a maleated polyolefin elastomer as a toughener," Polymer, vol. 46, no. 25, pp. 11600-11609, 2005.

[8] A. Dasari, Z.-Z. Yu, M. Yang, Q.-X. Zhang, X.-L. Xie, and Y.-W. Mai, "Micro- and nano-scale deformation behavior of nylon 66-based binary and ternary nanocomposites," Composites Science and Technology, vol. 66, no. 16, pp. 3097-3114, 2006.

[9] P. M. Gyoo, S. Venkataramani, and S. C. Kim, "Morphology, thermal, and mechanical properties of polyamide 66/clay nanocomposites with epoxy-modified organoclay," Journal of Applied Polymer Science, vol. 101, no. 3, pp. 1711-1722, 2006.

[10] P. Médéric, T. Razafinimaro, and T. Aubry, "Influence of meltblending conditions on structural, rheological, and interfacial properties of polyamide-12 layered silicate nanocomposites," Polymer Engineering and Science, vol. 46, no. 8, pp. 986-994, 2006.

[11] N. K. Borse and M. R. Kamal, "Melt processing effects on the structure and mechanical properties of PA-6/clay nanocomposites," Polymer Engineering and Science, vol. 46, no. 8, pp. 1094-1103, 2006.

[12] S. Mohanty and S. K. Nayak, "Effect of clay exfoliation and organic modification on morphological, dynamic mechanical, and thermal behavior of melt-compounded polyamide- 6 nanocomposites," Polymer Composites, vol. 28, no. 2, pp. 153$162,2007$.

[13] N. A. Hocine, P. Médéric, and T. Aubry, "Mechanical properties of polyamide-12 layered silicate nanocomposites and their relations with structure," Polymer Testing, vol. 27, no. 3, pp. 330-339, 2008.

[14] Y. Yoo and D. R. Paul, "Effect of organoclay structure on morphology and properties of nanocomposites based on an amorphous polyamide," Polymer, vol. 49, no. 17, pp. 37953804, 2008.

[15] B. Alexandre, D. Langevin, P. Médéric, et al., "Water barrier properties of polyamide 12 /montmorillonite nanocomposite membranes: structure and volume fraction effects," Journal of Membrane Science, vol. 328, no. 1-2, pp. 186-204, 2009.

[16] E. J. Garboczi, K. A. Snyder, J. F. Douglas, and M. F. Thorpe, "Geometrical percolation threshold of overlapping ellipsoids," Physical Review E, vol. 52, no. 1, pp. 819-828, 1995.

[17] http://www.nanocor.com/tech_sheets/N662.pdf, September 2008.

[18] http://www.scprod.com/product_bulletins/PB\%20Cloisite\% 2030B.pdf, September 2008.

[19] D. Adame and G. W. Beall, "Direct measurement of the constrained polymer region in polyamide/clay nanocomposites and the implications for gas diffusion," Applied Clay Science, vol. 42, no. 3-4, pp. 545-552, 2009.

[20] http://www.emsgrivory.com/mytools/datenblaetter/ datenblaetter/grilamid_tr/TR_90_E.pdf, September 2008.

[21] I. Y. Phang, T. Liu, A. Mohamed, et al., "Morphology, thermal and mechanical properties of nylon 12/organoclay nanocomposites prepared by melt compounding," Polymer International, vol. 54, no. 2, pp. 456-464, 2005.

[22] T. D. Fornes, P. J. Yoon, H. Keskkula, and D. R. Paul, "Nylon 6 nanocomposites: the effect of matrix molecular weight," Polymer, vol. 42, no. 25, pp. 9929-9940, 2001.

[23] T. D. Fornes and D. R. Paul, "Structure and properties of nanocomposites based on nylon-11 and -12 compared with those based on nylon-6," Macromolecules, vol. 37, no. 20, pp. 7698-7709, 2004.

[24] S. Xie, S. Zhang, F. Wang, H. Liu, and M. Yang, "Influence of annealing treatment on the heat distortion temperature of nylon-6/montmorillonite nanocomposites," Polymer Engineering and Science, vol. 45, no. 9, pp. 1247-1253, 2005.

[25] J. E. Mark, Ed., Polymer Data Handbook, Oxford University Press, Oxford, UK, 1999.

[26] http://www.emsgrivory.com/mytools/datenblaetter/ datenblaetter/grilamid_tr/TR_90_E.pdf, October 2007.

[27] T. McNally, W. R. Murphy, C. Y. Lew, R. J. Turner, and G. P. Brennan, "Polyamide-12 layered silicate nanocomposites by melt blending," Polymer, vol. 44, no. 9, pp. 2761-2772, 2003.

[28] P. I. Vincent, "The necking and cold-drawing of rigid plastics," Polymer, vol. 1, pp. 7-19, 1960.

[29] A. Cross and R. N. Hayward, "Thermal fracture of plastics," Journal of Polymer Science: Polymer Physics Edition, vol. 11, no. 12, pp. 2423-2439, 1973.

[30] A. Cross, M. Hall, and R. N. Haward, "Thermal effects in the necking of thermoplastics," Nature, vol. 253, no. 5490, pp. 340-341, 1975.

[31] J. W. Maher, R. N. Haward, and J. N. Hay, "Study of the thermal effects in the necking of polymers with the use of an infrared camera," Journal of Polymer Science: Polymer Physics Edition, vol. 18, no. 11, pp. 2169-2179, 1980.

[32] R. Roseen, "Temperature effect at self-oscillating necking during extension of polyethylene terephthalate (PETP)," Journal of Materials Science, vol. 9, no. 6, pp. 929-933, 1974. 



The Scientific World Journal

Submit your manuscripts at

http://www.hindawi.com

\section{World Journal}

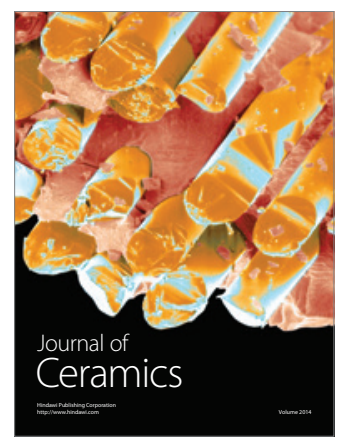

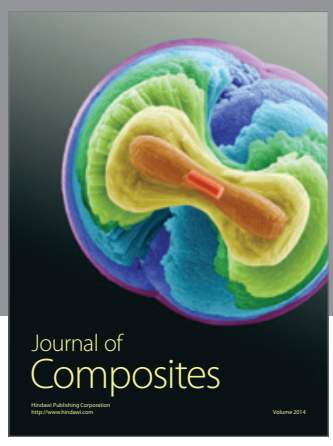
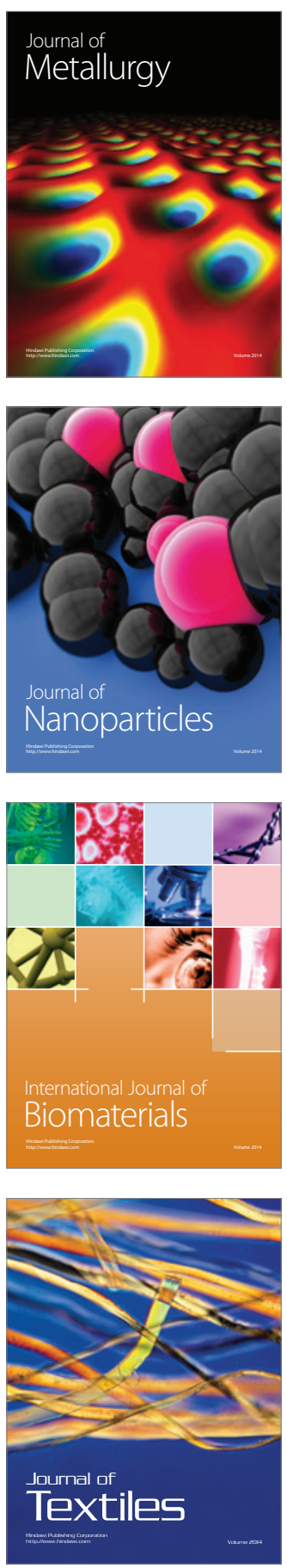